\title{
Management of the Documentation Release by the Programmable Electrical Energy Flow-Individually Made Machine Called Documentomat
}

\author{
Tomasz Chajduga *, Manuela Ingaldi (D) and Dorota Klimecka-Tatar (D) \\ Faculty of Management, Czestochowa University of Technology, 42-201 Częstochowa, Poland; \\ manuela.ingaldi@pcz.pl (M.I.); d.klimecka-tatar@pcz.pl (D.K.-T.) \\ * Correspondence: tomasz.chajduga@pcz.pl
}

check for updates

Citation: Chajduga, T.; Ingaldi, M. Klimecka-Tatar, D. Management of the Documentation Release by the Programmable Electrical Energy Flow-Individually Made Machine Called Documentomat. Energies 2021, 14, 5304. https://doi.org/10.3390/ en14175304

Academic Editors: Edmundas

Kazimieras Zavadskas and

Valentina Colla

Received: 1 July 2021

Accepted: 17 August 2021

Published: 26 August 2021

Publisher's Note: MDPI stays neutral with regard to jurisdictional claims in published maps and institutional affiliations.

Copyright: (c) 2021 by the authors. Licensee MDPI, Basel, Switzerland. This article is an open access article distributed under the terms and conditions of the Creative Commons Attribution (CC BY) license (https:/ / creativecommons.org/licenses/by/ $4.0 /)$.

\begin{abstract}
It is well known that in a turbulent world (full of processed information), information has a particularly high value. Wide access to technology makes the data transformation and transmission processes faster and more vulnerable to leaks and unauthorized access. This publication discusses the concept of information security management based on a development of a machine called documentomat. It is the machine built to automatically release documents with regard to high security standards. The entire flow of the documents in the company has been presented and the formalized process of decision-making to develop and finally build above-mentioned machine was described. The problems and doubts raised during the machine building process were presented along with the solutions adopted. The device has been designed, constructed, and programmed within the resources of one micro-sized limited liability company in Europe. Thus, it is the solution working in a real world that may find application in many similar companies, not the theoretical concept only. The final result exceeded the expectations of the project team, leading to strengthening of the competitive position of the company. This occurred through the following aspects: adding significant advantage to its offer, which is the ability to release the documents at any time with regard to high security standards. Moreover, the long-term level of costs of such a solution seems to be very low. During the one year of operation period, two malfunctions took place, each was repaired in just $3 \mathrm{~h}$ (repair and improvement, labor only, no spare parts needed). Any further maintenance, repair, or development can be done at very affordable prices, at non-available on the market labor cost, which will potentially further strengthen the impact of the solution on the competitiveness of the company. Improvement in terms of competitiveness of the company and data safety has been gained. The success of this project proves that, in some cases, it is worth to develop the necessary solution within the resources of the company rather than buying one from an external enterprise.
\end{abstract}

Keywords: programmable machine; management of document flow; information security; electrical energy; automated releasing of documents; data security; electromagnetic locking mechanisms

\section{Introduction}

\subsection{Background}

Nowadays, filled with numerous data streams, information has a particularly high value. In fact, information and its flow may have a direct impact on the development of various technologies, and what is more, it may affect the development of technologies controlling the analysis of data contained in the information. Generally, wide access to technology makes the data transformation and transmission processes extremely quick and vulnerable to leaks and unauthorized access [1,2]. On the other hand, users of information are expecting easy access with a multitude of electronic means [3], with implemented standards ensuring a sufficient level of security $[4,5]$.

Information security is the process of information protection in order to ensure its separation against various intentional and unintentional threats like data theft, power losses, 
ransomware encryption, unauthorized access, etc. [6]. The information security management and the construction of related systems are regulated by the ISO/IEC 27000 family standards: ISO/IEC 27001, ISO/IEC 27002 [7-9]. The ISO/IEC 27001 standard, Information Technology, Security Techniques, Information Security Management Systems Requirements [8], defines the requirements for the establishment, maintenance, implementation, and continuous improvement of the information security management systems, with regard to the circumstances where the organization operates. It also provides requirements for estimating and dealing with risks in information security. This standard is the canon of information security and is used throughout the world. The ISO/IEC 27002 standard is called Information Technology, Security Techniques, Practical Information Security Principles. It contains recommendations on information security standards in organizations and information security management practices.

Large enterprises and well-organized corporations have introduced the principles of information flow management a long time ago, but nevertheless, still in many enterprises, despite the great involvement in information management (and documents as information carriers), there is a lack of tools and equipment for effective, efficient and, above all, safe information flow - this usually applies to small and medium-sized enterprises (SMEs) [10-17]. The purpose of this article is to present how the design of the document transfer device has been developed. In the article, science meets practical application. As a result of brainstorming and needs analysis, a machine called documentomat was designed. The documentomat is a device that is programmed based on the company's border requirements and is customized to the company's needs. In the machine, the programmable modules, electrical and electromagnetic energies have been used to ensure the high level of data security. The main assumption of the documentomat is to support a company's information management system. In order for communication to be effective, a documentation circulation plan should be created that will allow organizing work in the company. Such a plan should include selecting appropriate forms of communication (document circulation), determining the needs of addressees and recipients, and determining the verification of the effectiveness of the plan.

It must be stated that this article is the development and more practical approach to the subject of a pilot article published in 2019 entitled "Information security management in an individual documentomat project" [18].

\subsection{Information Management}

Information is the most valuable property that each enterprise, organization, or economic unit have. Its proper placement guarantees the enterprise development in a very turbulent, demanding, and expansive global market. Information management is nothing more than controlling the flow of information processes in order to optimize them. Information management covers both the stage of creating information and organizing its flow, development, storage, distribution, and use $[19,20]$. Information is a very valuable resource, and the method of its generation may vary and depends largely on the maturity of business processes in the enterprise [21-24]. In recent years, in the face of the revolution 4.0 approach, generating data and creating a set of information resulting from the analysis of this data is part of the strategy of every enterprise. The growing importance of information as an economic resource and a competitive component means that information has become indispensable for the legal functioning and development of an organization. Valuable and timely information increases confidence in making the right decisions [25].

\subsection{Development of a Document Management System}

The enterprises are increasingly interested in the careful management of private information. In particular, when the companies comply with the law providing the security maintenance of transferred and stored data. At the same time, the extensive scope of information transfer (the need to document at every operational level) makes the management of documents (as information carriers) more and more difficult. The effectiveness 
and correctness of the document management system is largely determined by organizational strategy, human resource management, and knowledge management. Highly developed (systematized) business processes in this area guarantee a quick implementation of a document management system, which in turn significantly improves the standards of organization management [26-32].

One of the methods of document management is the necessity to create an effective internal document management system [33]. The document management system provides the possibility of quick access to a wide range of information, and additionally supports the possibility of secure access to documents-document management system facilitates the management and sharing of information. Besides security, the goal of a document management system is to extend such sophisticated functions and simplify complexity for users and applications in the organization [34,35]. In addition, the creation of interorganizational systems (IOS) accelerates communication with various units of one company or with cooperators available information resources favor building strong and compatible flows (both material and non-material) of resources [36]. The entire document management system includes: storage, annotation (specifying, indexing), content control, access control, version control (change control), access control (restriction of access) to full versions of documents, and data security Figure 1 [37].

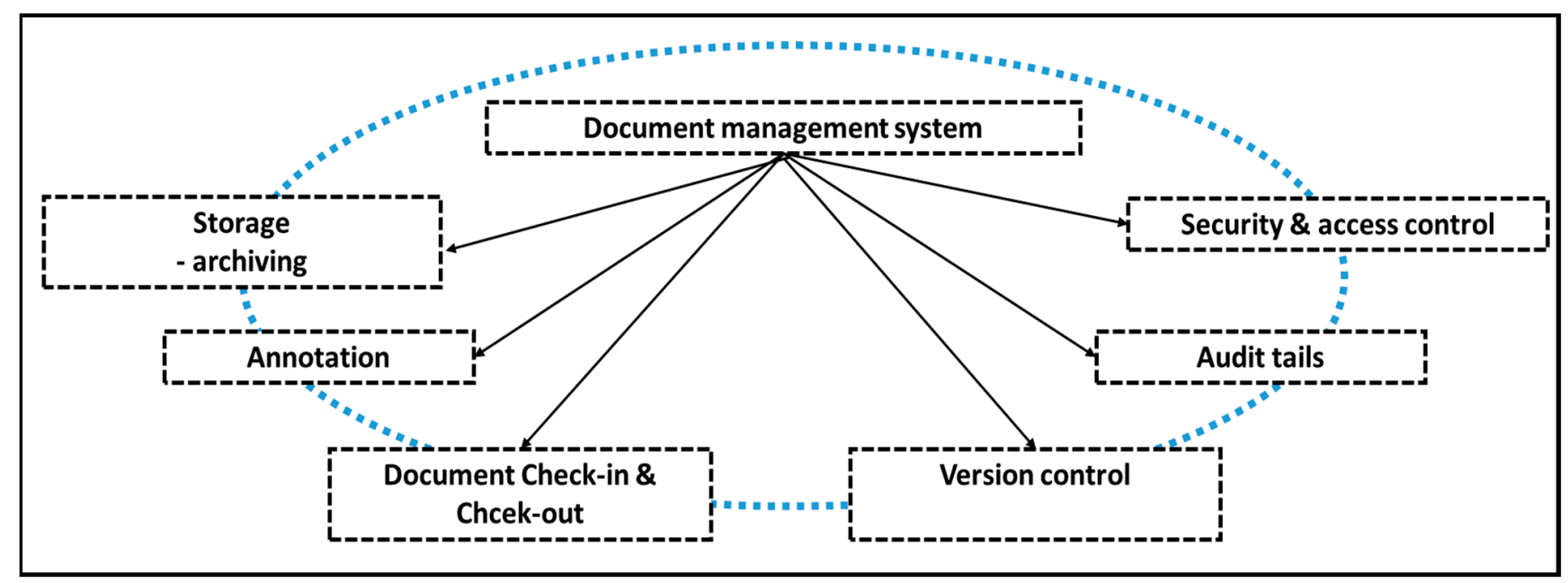

Figure 1. The document management system—general model.

The research results carried out by Ayaz et al. [38] have shown that the use of a document management system in enterprises has a very positive effect on the results of work. Moreover, the efficient functioning of the document management system (which results in the acceleration of data flow) largely depends on the operation of supporting devices, for example, equipping the device with an "intuitive" and ergonomically designed interface. In addition, training and support from higher-level employees improves communication inside the organization, accelerates the process of generating documents, fosters the detection of errors and deficiencies, and many activities take on a systematic nature [38,39]. Each document management system should consist of three basic cells (subsystems): (1) data storage system, (2) content management system, (3) consumer storage service [40-42].

The results presented by Kapler [43] prove that in running SMEs in the field of financial services-where the flow of data and information is the most important-there is still considerable reluctance in terms of social acceptance of modern information technologies. On the other hand, the results of Ingaldi and Klimecka's [44] research prove that, in general, society is resistant to modern technologies, despite the fact that it is known that modern technologies are the only correct direction of enterprise development.

In the literature of the subject, the authors noticed a small gap, which is a practical communication system (module) that can be implemented in enterprises of various sizes. 
Most of the solutions proposed in the literature refer to expensive and complicated system solutions, the price of which makes them available only to large enterprises [45-50].

There are many types of business document production schemes in the circulation of any enterprise that can be classified based on general reference classes. The most important classes include [43,51-53]:

1. Business documents must contain predefined data sets. For example, an invoice, an e-invoice containing contractor data-company name, tax identification numbers, amounts due, bank account numbers, etc.

2. Business documents, the arrangement and labeling of which depends on the internal arrangements of the company-diagrams and defined layouts.

3. The designation and structure of business documents are provided with keywords.

\subsection{Communication in the Organization}

The communication process begins at the moment of the potential sender's intention, in the form of thoughts or a desire to convey information to the recipient. However, the information can take many forms. The goal of communication is to create direct communication channels that facilitate cooperation. Communication in the organization includes vertical, horizontal, and network communication. Vertical communication takes place between employees at different levels, e.g., between a manager and an employee. On the other hand, horizontal communication is characteristic of project teams, which takes place between group members.

Particular difficulties in communication can be noted in small and medium-sized enterprises (both production and service). Such difficulties result from the specificity of the management of the SME sector. An insufficiently developed organizational culture, aversion to modern technologies, and insufficient financial sources are the most important of the known barriers appearing in modern enterprise management. According to Stacho et al., the frequency of attending communication trainings and the level of the support of employees in bottom-up communication influencing informal communication in organizations [54]. The appropriate level of communication and information flow additionally significantly influences innovative activities in each organization. This is due to the fact that most of the barriers and complications in enterprise management are the result of ineffective or unreliable communication-especially between various units (internal and external) of the organization involved in the process. In addition, the choice of communication media affects the satisfaction with internal communication, and companies that put more effort in adapting their media to the needs of employees have a satisfied internal audience [55-58]. Internal communication issues are largely grounded in public relations theories and are often used in research on internal communication [59].

\section{Development of the Concept}

The enterprise is a micro-sized limited liability company located in Katowice, Poland. The company focuses mainly on the data processing area, with over a hundred European clients (other limited liability and joint-stock companies, foundations, and associations). The main task of the company is the accurate processing of current data, mainly correspondence, therefore, the core processing stage must be highly confidential and ensure a high level of quality (i.e., adequate to each client's expectations). Side processes, in turn, concern both planned activities, such as periodic dispatch of documentation, issuing it to customers' representatives, assistance in establishing companies in Poland, as well as non-standard tasks, i.e., meeting additional customer expectations, depending on the current situation and basing on conclusions drawn from the currently processed data. First of all, the company had decided to analyze its documentation circulation system in order to realize its strengths and weaknesses. Figure 2 represents a diagram of the documentation flow throughout the company. 

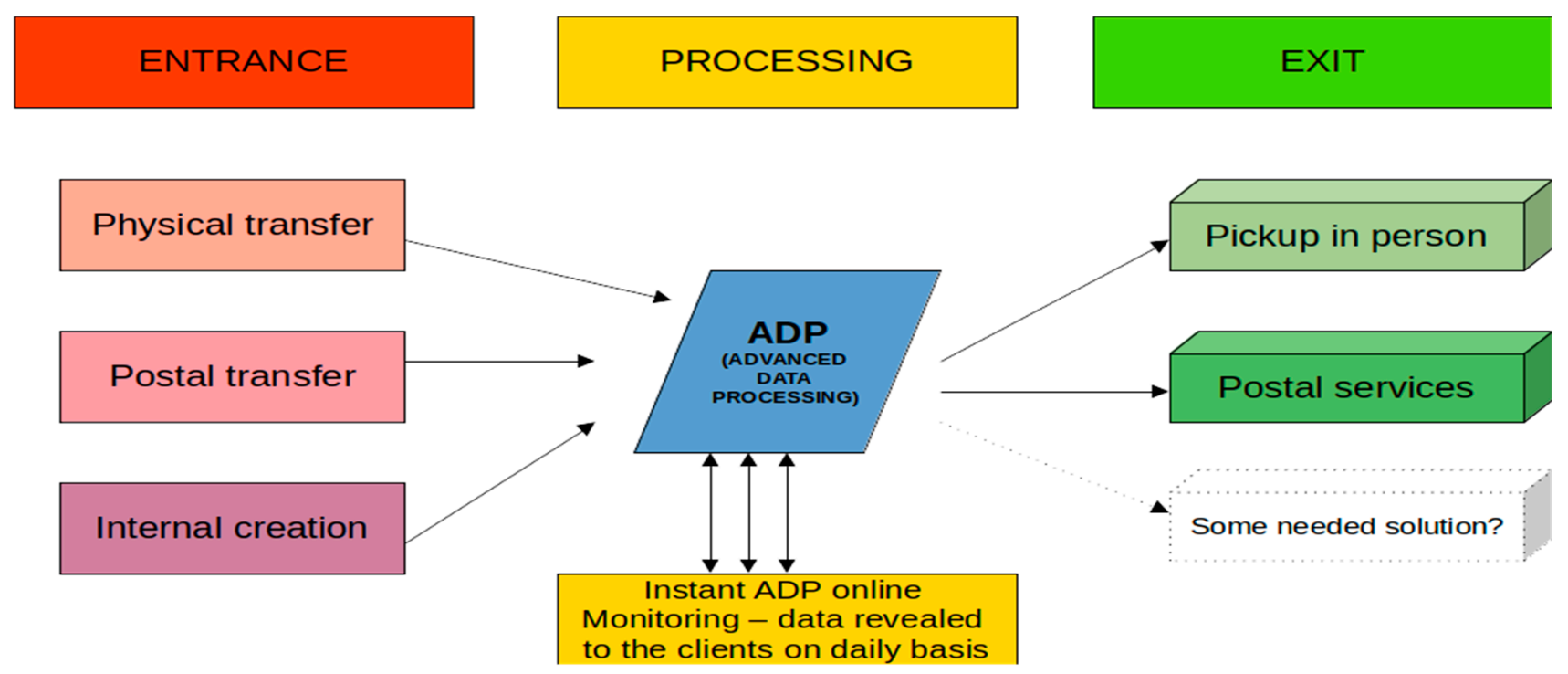

Figure 2. The document flow throughout the company.

To begin, there are three ways that the documentation can be found in the company. The first one is, when client company simply pass the documentation to process. Second, when clients of the client send their documentation directly to the company in order to process it to the client. Third, the documentation may be created in the company as a result of data processing. On the other hand, processed documentation is stored and released to the client with previously settled manner. It can be either sent by a postal service in a scheduled way (once a week) or revealed to the client in the spontaneous way if they ask for it.

The problem occurs when some client decides to collect the data (documents) as soon as possible but is not able to receive it in the office working hours. Then, any sending by post office or courier services would be a waste of time. The company had organized a brainstorming session to bring awareness to the possible options-Table 1.

Table 1. The outcome of a brainstorming session.

\begin{tabular}{cr}
\hline Number of Idea & The Concept of Solving the Problem \\
\hline Idea 1 & Employees may take the documents home and give it to clients before or after office opening hours. \\
\hline Idea 2 & The company could have its own courier department in order to deliver it to its clients. \\
\hline Idea 3 & $\begin{array}{c}\text { The company could dedicate additional employee in order to ensure } 24 \text { h document releasing service at the } \\
\text { company office place. }\end{array}$ \\
\hline Idea 4 & $\begin{array}{c}\text { Additional cooperation could be established between the company and the security company at the office } \\
\text { place- the security could be engaged into document giving process while company office is closed. }\end{array}$ \\
\hline Idea 5 & Another automated solution could be potentially developed.
\end{tabular}

Because the method of brainstorming has the assumption not to criticize the emerging ideas, the next part of analysis has been enriched with the aspect of criticism-the ideas have been discussed during several internal company meetings. The criticism was presented in Table 2.

To prevent hasty decision-making, each idea has been graded within the recognized (above-mentioned) aspects. Prior to the grading process, each respondent had conducted his or her personal research in the focused area, based on self-knowledge and network of contacts developed in the course of their professional life (professionals in data processing industry). A few employees had additionally sent inquiries (about the necessary solution) to external companies specialized in data processing or automation. The results of personal 
research are described below. The main producer (the global leader) of similar solutions is the Inpost Sp. z o.o. (Polish limited liability company). However, its solutions are designed strictly for parcels, not for documentation. There is a legitimate concern that a solution designed for parcels might turn out not to be safe for documents. The reason is that the package of documents may be very thin. Moreover, because Inpost produces solutions for its own purpose becoming the international leader in delivery services, they are not revealing any technical information about their machines. During unofficial disputes conducted with professionals from the automation industry, they had revealed that each industry they work for has its own preferred producer of components used to automate its processes. In a private talk, Johnson Controls, Rockwell Automation and Pratt \& Whitney were pointed out as the leading automation suppliers. Professionals were reluctant to talk about the cost of the components supplied by the aforementioned companies, claiming that they were "far beyond the micro-firm's budget". To be more specific about what they mean, the cost of components of professional automation suppliers required to build the machine would be about 30 to 50 per cent of yearly income of a micro-sized company.

Table 2. The critical approach to the ideas emerged during the brainstorming session.

\begin{tabular}{|c|c|}
\hline Idea & Criticism Expressed by Employees \\
\hline Idea 1 & $\begin{array}{l}\text { The idea is bad, because it makes employees "working after work". This could make them less focused on the job in } \\
\text { working hours. Another disadvantage is the fact that such a solution requires the another remuneration option to } \\
\text { engaged employees, which entails additional costs for the enterprise. }\end{array}$ \\
\hline Idea 2 & $\begin{array}{l}\text { This solution is bad, because it raises costs significantly. As a result of the internal analysis, it was proved that this } \\
\text { solution would not be possible to implement without the rise in prices for final clients. The assumption is to find the } \\
\text { solution to enrich the company offer and make it more attractive. Not better, but finally more expensive, too. }\end{array}$ \\
\hline Idea 3 & $\begin{array}{l}\text { The main disadvantage of this solution is poor supervision of the single person working in the office alone all the } \\
\text { night. Moreover, the additional cost of the dedicated person would have to be paid. }\end{array}$ \\
\hline Idea 4 & $\begin{array}{l}\text { This idea distributes the responsibility between two companies, which leads to entrusting data to persons that } \\
\text { influence on is very limited. Besides, implementation of such an idea is also generates significant costs each month. } \\
\text { Price increase would be unavoidable. It also transfers the responsibility for delivering documents to external parties, } \\
\text { which is more difficult to control. }\end{array}$ \\
\hline Idea 5 & $\begin{array}{l}\text { The main disadvantage of this idea is that it can be very expensive if external company be asked to build a suitable } \\
\text { machine, otherwise, it may turn out to be quite time-consuming for the engaged person. }\end{array}$ \\
\hline
\end{tabular}

The number of disputes between employees and management of the company has led to choosing the most important aspects of each idea, which can help the decisionmaking process and give the final grades. They were supposed to evaluate all these aspects on a 10-point scale, where 10 is the best value. In the evaluation, 20 people took part (15 employees and five clients). Next, all aspects and grades were presented to five chosen important clients. The purpose was to engage in the decision-making process a wider scope of stakeholders. The clients have rejected idea 1 unanimously, because they would not like to accept the solution based on overusing the company's employees, as they say. During the disputes, idea 5 has been split into two separated ideas:

- 5-Automated solution could be potentially developed by external company

- 6-Automated solution could be potentially developed within the company

The results of the evaluation process of each idea are presented in Figure 3 (detailed results) and Figure 4 (total results). In case of the detailed results, the radar chart was chosen. As mentioned before, all examined aspects were evaluated on a 10-point scale, which allowed us to show the obtained results in the form of a field. The higher the evaluations, the larger the coverage area of the radar chart, which is evident in case of idea 6 . The bar graph was used to show the difference in total evaluations between individual ideas. 
(a)

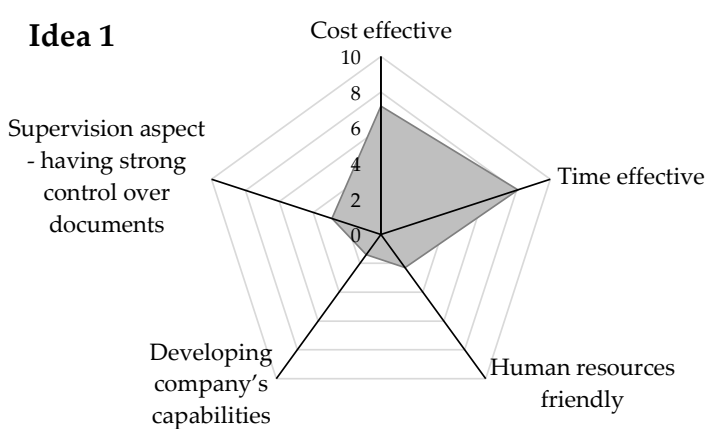

(c)

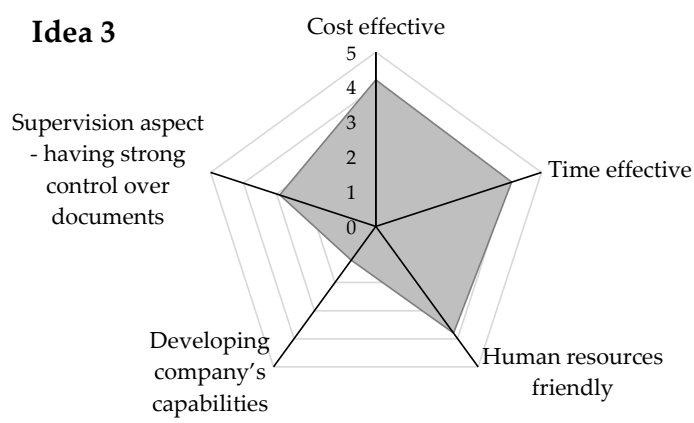

(e)

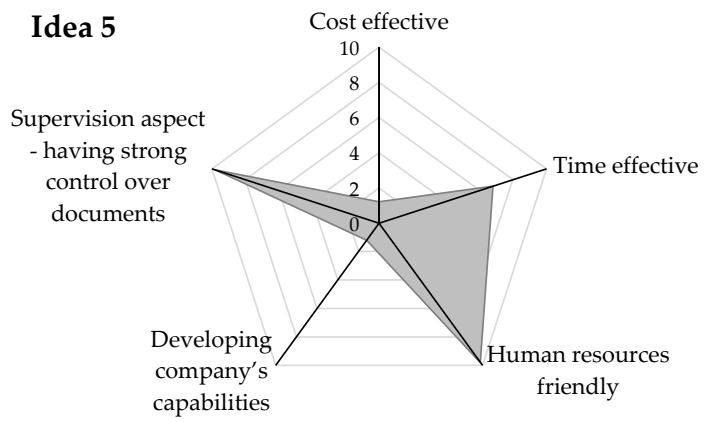

(b)

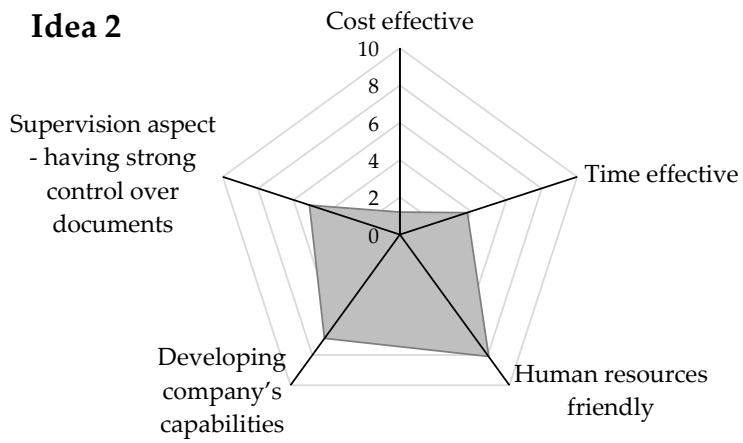

(d)

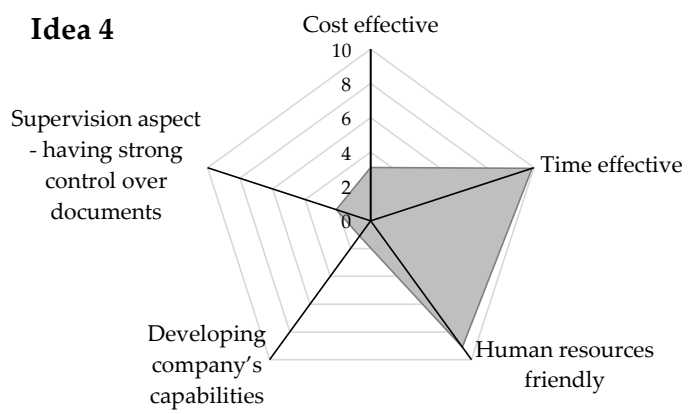

(f)

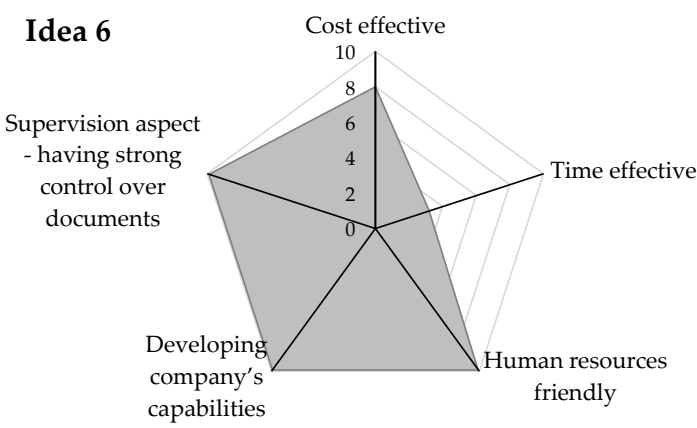

Figure 3. The detailed results of evaluation process among main stakeholders of the company: (a) Idea 1; (b) Idea 2; (c) Idea 3; (d) Idea 4; (e) Idea 5; (f) Idea 6.

Finally, idea 6 has been chosen: automated proprietary solution will be developed within the company. Therefore, the hypothesis was formulated that the creation of an appropriate device that meets the assumed (mentioned in the text) criteria is possible within the resources possessed by a micro-sized company. The additional general assumptions have been made: the employee working on such a solution will spend time when the workload is low, not working too much or on overtime. The priority must be put on development of company's capabilities at a moderate cost, with no pressure on time. The long-term cost-effectiveness can be obtained also through deep knowledge about the developed solution - the ability to perform cheap modifications, repairs, as well as maintenance/service at an affordable cost.

At the point when the decision about the development of proprietary solution has been made, the engaged persons have chosen the employee that was the strongest supporter of the proprietary automated solution idea as an individual responsible for the entire project. The formalized assumptions were written in order to ensure a methodological and rational approach to the project realization to ensure long term correlation with company goals of the project. 


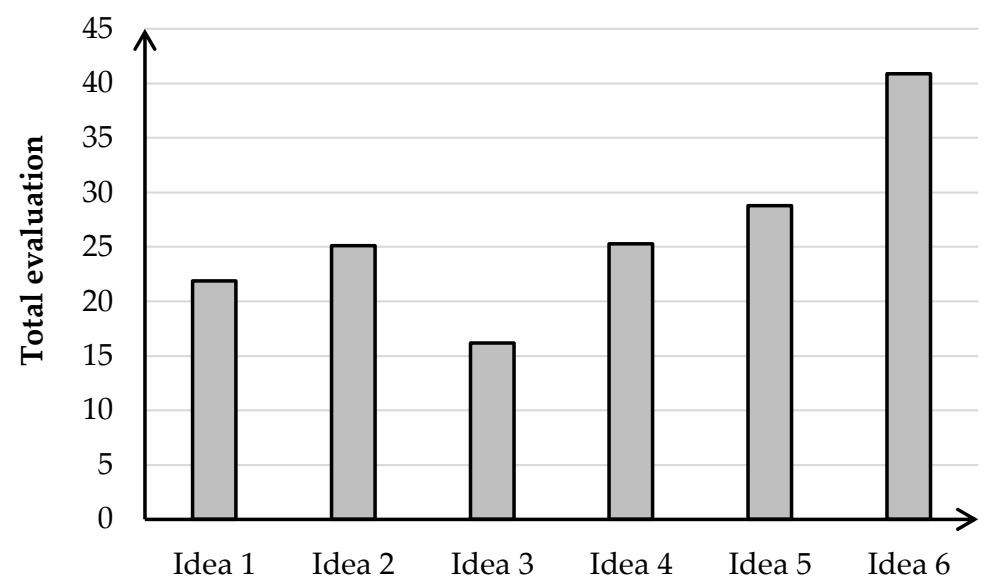

Figure 4. The total result of the evaluation process among main stakeholders of the company.

Assumption 1. Individual responsible for the project is obligated to work on the project not more than one weekday (8 working hours in total each week).

Assumption 2. The individual responsible for the project is obligated to report progress (or arising problems), share the doubts, and ask other employees if some important decision to be made in the time range from $15 \mathrm{~min}$ (for simple information sharing, f. ex. reporting the progress) to $60 \mathrm{~min}$ (15 min of problem description, $30 \mathrm{~min}$ for discussion and 15 min for final decision-making with voting possible, if needed) each week.

Assumption 3. The development process is planned to last for about one year and any necessary decisions will be taken later with respect to the progress pace and generating cost. The company will support the development process with the necessary equipment and materials.

After the period of two months, which corresponds to about eight working days of research, the general vision of the solution was made. The solution was a machine equipped with electromagnetic locks controlled by electric energy thorough the programmable microcomputer in order to open it in a secure way. The following development process has brought further decisions about the machine and its system. All the necessary subsystems are described below.

The authors recognize the outcome of 20 people survey as valuable and significant because of no randomness of the research sample. Each individual engaged in the decision process was also a professional in the data processing area. Moreover, these individuals were specially prepared because of personal research they previously made and the effect of synergy occurred when they exchanged the information they had required. Moreover, all of them were related to the company, understanding its situation and needs. For abovementioned reasons, the sample size is not that important in this case. The professionals easily understood that buying a solution from another enterprise would be very unreasonable decision for a micro-sized company, while the decision made, despite being brave and risky, turned out to be right. The scientific input of this case is to show to other companies and give an example of how to use the internal company resources and relations with stakeholders (clients) in a better way, to gain or improve the company's competitiveness and strengthen the long-term core competence of the company.

In the following part of the article, the standardized units of measure will be used to present the parameters of specialized devices: V [Volts], A [Ampers], ms [milliseconds], mm [millimeters], F [Farads], etc.

\section{Results and Discussion}

First of all, the skeleton of the machine. It was made of a 3-mm-thick sheet of steel plate secured with anti-corrosion laminate. The thickness is important to ensure the safety of the construction. The company equipped the responsible employee with the necessary 
tools, enabling bending and cutting the sheet of plate. The skeleton was made to cover the documents from each side with metal; this is what the real security is about.

What is more, the general power supply into the machine must be solid and secured. An electric safety strip was built into the machine to separate the internal electronics from the electrical shocks or any peaks of voltage that could result in instability of functioning.

Next step was the choice of locks opened with usage of electromagnetic energy. The locks must be precise and solid. Its nominal operating values are $12 \mathrm{~V}$ and $2 \mathrm{~A}$ of direct current to open. If closed, locks do not need any power supply. This is an important feature, because documents should be safely locked in case of power loss. Moreover, during the development process it became clear that it is expected that the entire system of the machine should be rather power saving and ecological friendly, that is why all the solutions used in the machine must maximally reduce power consumption when on standby. The experimental measurement was made. The experimental usage of electromagnetic lock showed that it consumes less than nominal $2 \mathrm{~A}$ of a direct current, with the tendency to fall with time if the lock is used more and more, thusm $2 \mathrm{~A}$ can be treated as a maximal value. Moreover, it can be noted, that the pace of usage of the electromagnetic locks in time is the result of the time they are opened each time, as with time passing the current they consume falls down. This is the premise to support the system with precise mechanism controlling the opening of the locks (boxes). Figure 5 presents the electrical and electromagnetic energies used in order to open the lock.

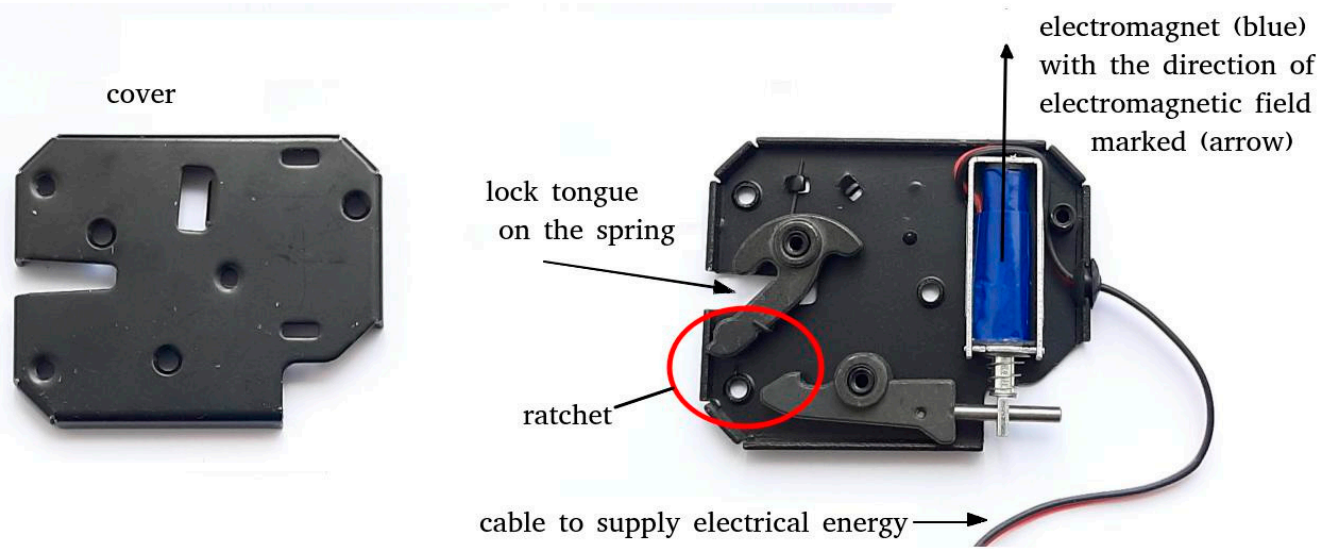

Figure 5. The internal structure of the electromagnetic lock with description.

In order to connect the electromagnetic locks with the source of power, the machine had to be equipped with the additional power adapter. The precise purpose of usage of the power adapter is to transform sine-wave electrical current with parameters $230 \mathrm{~V}$ and $50 \mathrm{~Hz}$ into a power friendly to the electromagnetic locks, $12 \mathrm{~V}$ and a maximum $2 \mathrm{~A}$ of direct current.

It must be stated that power with a current about $2 \mathrm{~A}$ is too strong to be controlled by a microcomputer directly. The majority of electronic circuits nowadays is too delicate and could burn and be irreversibly defected after contact with such a current. The other circuit is required to separate the comparably high current enabled to power electromagnetic locks from delicate control signals coming from the programmable microcomputer. The specialized KSH122 transistors made by Fairchild Semiconductor have been chosen to perform such separation and control the $2 \mathrm{~A}$ current. The main parameters of transistors are: $8 \mathrm{~A}$ collector current (16 A if pulse), $120 \mathrm{~mA}$ base current, $5 \mathrm{~V}$ emitter-base voltage. The maximal current they can control is $8 \mathrm{~A}$. The difference between $8 \mathrm{~A}$ and $2 \mathrm{~A}$ is enough to provide a long time of service without malfunction. However, it is important to indicate that a transistor, as an electronic element, usually generate heat when operating close to its limits, but in this case, each electromagnetic lock will be energized and open for a fraction of second, precisely what is required to release the doors of the metal box. The precise time 
control is crucial to have operating experience without an additional cooling system for the right energy dispersion. Figure 6 presents the chosen transistor model with description of its pins.

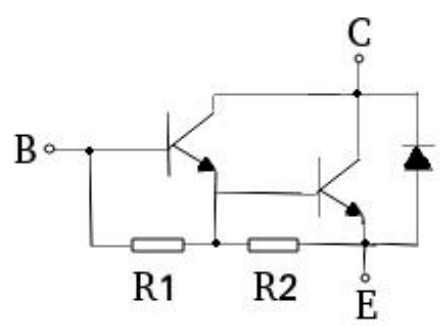

Figure 6. The equivalent circuit presenting the internal structure of NPN Silicon Darlington type Transistor KSH122 manufactured by Fairchild Semiconductor finally used to control the electromagnetic locks (B stands for base, $\mathrm{C}$ for collector, and $\mathrm{E}$ for emitter).

The transistors in the presented solution are working in the function of a switch opening the electromagnetic locks precisely when needed for the time of $2 \mathrm{~ms}$. Transistors were used as connection of relatively weak, sensitive signals from the controlling microcomputer with much stronger signal directly used to control the locks.

In terms of programmable controlling unit (microcomputer), the Raspberry PI B with the ARM micro-controller has been used (Figure 7). The advantages of this device are:

- $\quad$ it is a power saving solution, easy to operate at low voltage and to cool down with passive cooling;

- $\quad$ the circuit is equipped with GPIO pins (General Purpose Input Output pins) and programmable with popular programming languages, f. ex. Python and C\#;

- the microcomputer is powered directly from the micro-USB adapter or power bank;

- $\quad$ the device is equipped with many widely used industry standards, for example Wi-Fi, HDMI, and USB ports enabling easy diagnostics and development, if required;

- the microcomputer has a built-in audio card and jack output, which gives an additional way of informing the user of the state of the device.

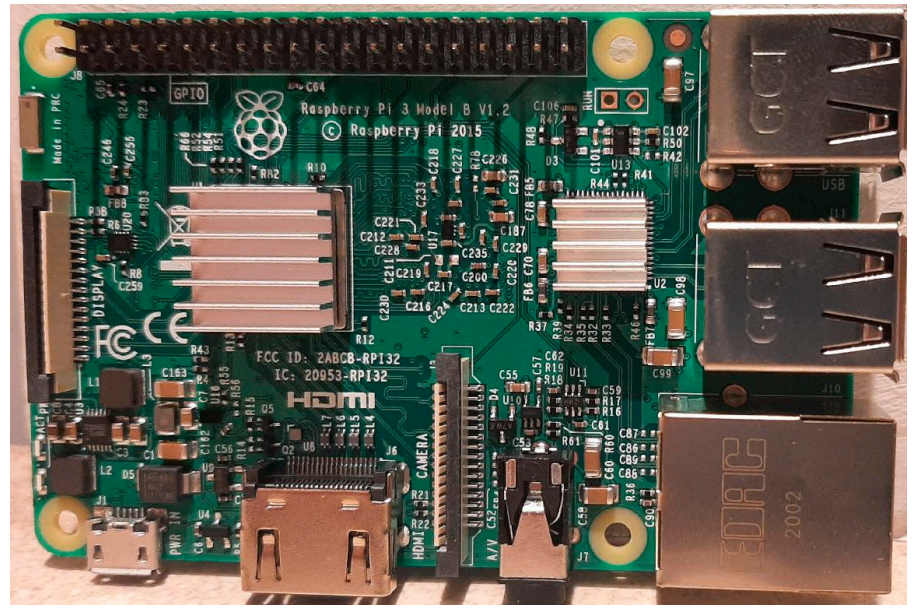

Figure 7. A photograph of Raspberry PI B solution used in the machine.

The microcomputer was programmed with Python programming language using 512 lines of code (including comments). In general, the code implemented most important functions: to save the opening code in the database (it is called the service mode) and to verify if the inputted code is equal to saved value (client mode). Figure 8 presents the fragment of the code. The presented code is important because its execution results in saving the number of the locker in the access codes in the database. The device confirms 
this by playing a "beep" and printing the text "data is saved" on the service screen (if connected). This gives the opportunity for communication with the machine and makes maintenance easier.

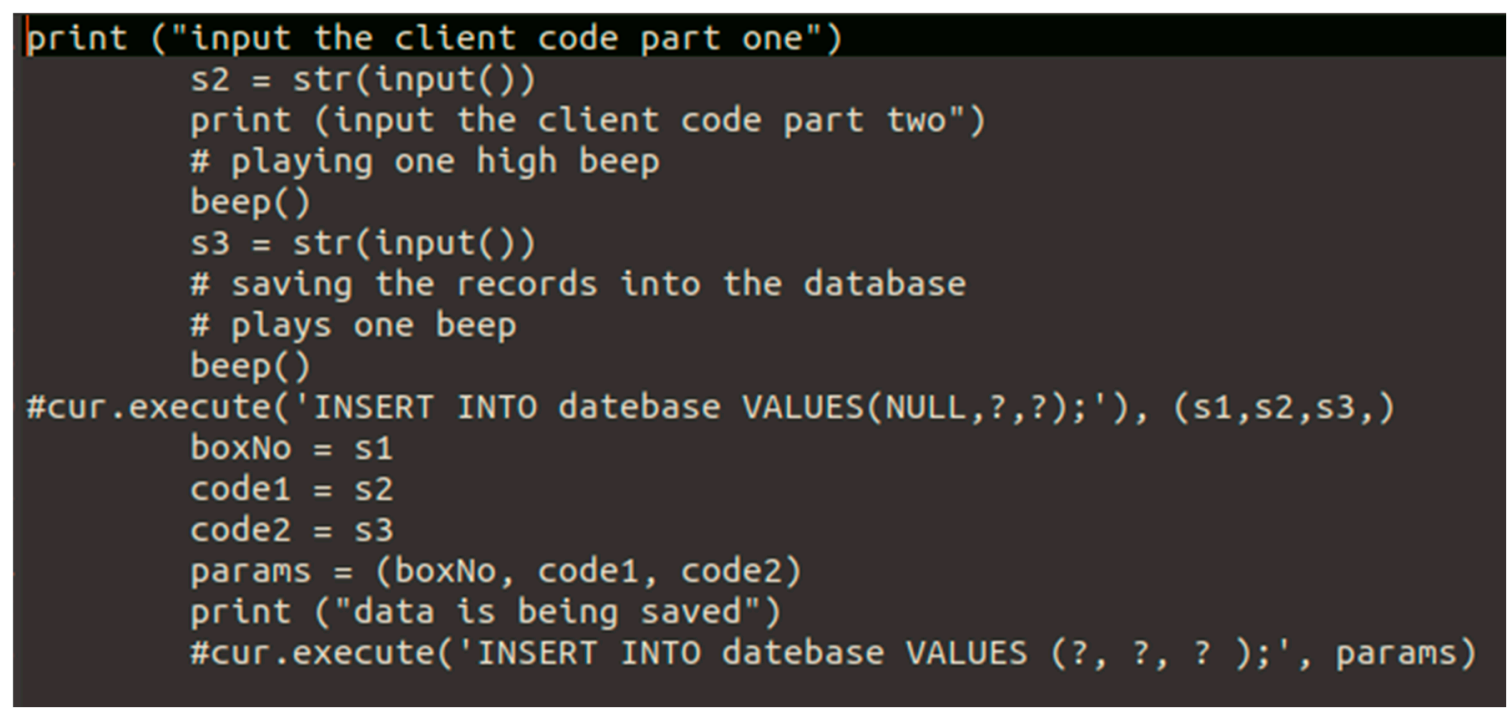

Figure 8. The fragment of the code in Python programming language.

The pseudocode of the entire Algorithms 1 is presented below:

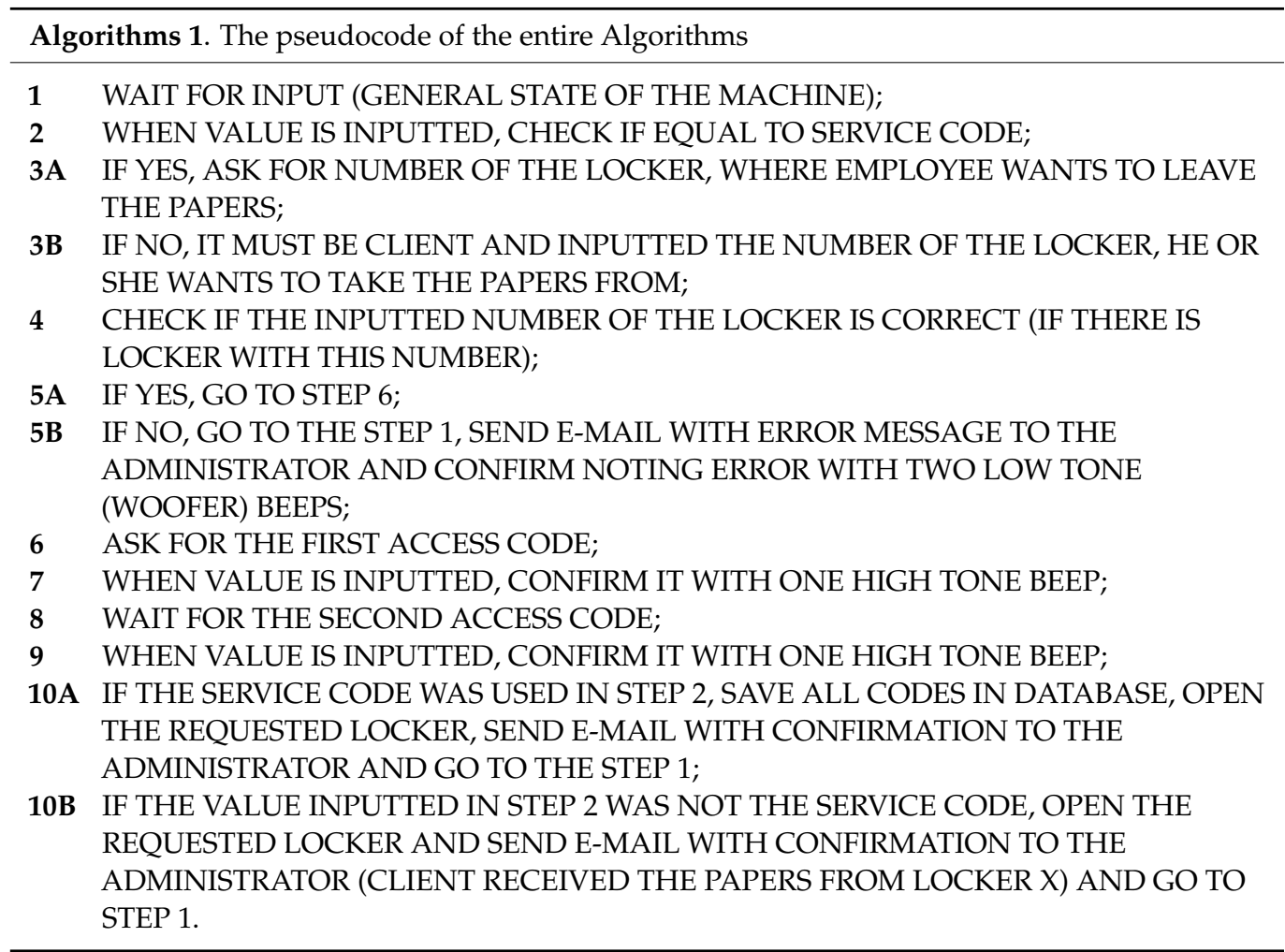

In detail, the machine is in the standby mode for the vast majority of time. It means, it is powered on, and the keypad is connected to the microcomputer, minimal power is used. Locks are in the locked positions, preventing access to the boxes.

In order to leave the documents in the box, the employee (user) must open the box. It means the service mode must be used. In order to do so, he or she inputs the service code (that is known to employees only, not to customers). The microcomputer is equipped with 
internal sound card. That is why playing sounds is possible. The software plays unique signal informing that the service code has been accepted, and the machine is going to learn (record in the database) the opening code. Alternatively, the two low beeps are played to inform that the code is wrong, and the software starts waiting for the next try again. If the right code has been inputted, the machine is waiting for the instructions of the employee. First, the number of the lock to release must be inputted. In practice, the employee enters the number of the steel box to open. They finish by pressing enter. If the right (existing) number of the lock/box has been inputted, one high beep can be heard (or two low beeps, if not). After having inputted the number of the lock to open, the machine waits for the six digit secret code that is going to be revealed to the authorized client's representative only. At this point, the machine cannot deny the code (no possibility of playing two low beeps) because it is in the state of learning (recording the secret code). It means, every possible code is going to be stored and accepted. The successful finalization of the saving data process (recording the number of the lock and the access code) is signalized with playing the unique sound again and opening the right lock, giving access to the box that the employee asked for. The unique sound is played two times: when entering and exiting service mode only.

The customer, after requesting to collect the documents out of working hours, is informed about a suitable secret code to open the box with required documents. In the case of the most crucial and data-sensitive documents and data, the code can be split in two: the first part can be sent via SMS (or spoken in the phone call) and the second, f. ex., by e-mail. The representative from the customer side must use the client code in order to open the right box. To do so, he or she must input the number of the lock (box) first. He or she will be hearing one high beep if the right number was inputted or two low beeps in opposite situation. The high beep is the invitation to input the most secret part of the code, while the two low beeps are an invitation to try again. Final insertion of the proper secret code is notified by high beep and releasing the requested lock opening the box with the documents. From this moment, the machine turns into the standby mode, again waiting for the next set of codes.

In order to ensure the smooth operation of the microcomputer, the assistive power bank with a set of capacitors have been added. The power bank is Tronsmart Bolt $5000 \mathrm{mAh}$. In case of power loss, it sustains power for the microcomputer for about $5 \mathrm{~h}$ in standby mode. The set of capacitors has been added, because empirical tests revealed that (in about $10 \%$ of cases) the power bank cannot switch fast enough from the state of being charged to the state of supporting energy. This resulted in unplanned restart of the microcomputer, which always should be avoided. The total capacity of the set of capacitors (in parallel layout) was determined during empirical test and equals to about $8 \mathrm{kF}$, which eliminates the above-mentioned problem.

Finally, the additional stereo amplifier has been added to extract clear sound and improve the user experience of the finally built machine.

Figure 9 presents all the elements connected in the one coherent system of the machine to automated distribution of documents, which can be called documentomat. The electrical energy is distributed from an AC adapter to a power bank and a set of capacitors and to an additional power source. The power bank with a set of capacitors ensures stable power for the microcomputer while the additional power source supplies power to the high current circuit-it means it provides power to the electromagnetic locks (presented is just one lock for simplification of the picture). The locks are controlled by signals coming from GPIO pins from the microcomputer. Signals need to be strengthened through the transistor's circuit (low current turns into high current). Obviously, the microcomputer uses the USB ports to connect with the wireless keyboards and is connected to a $\mathrm{Wi}-\mathrm{Fi}$ network. Moreover, the microcomputer uses a micro-controller to process inputs from the keyboards and execute the program in Python language. The audio connector is used to pass the analog audio signal into the amplifier and, finally, to the speakers. 


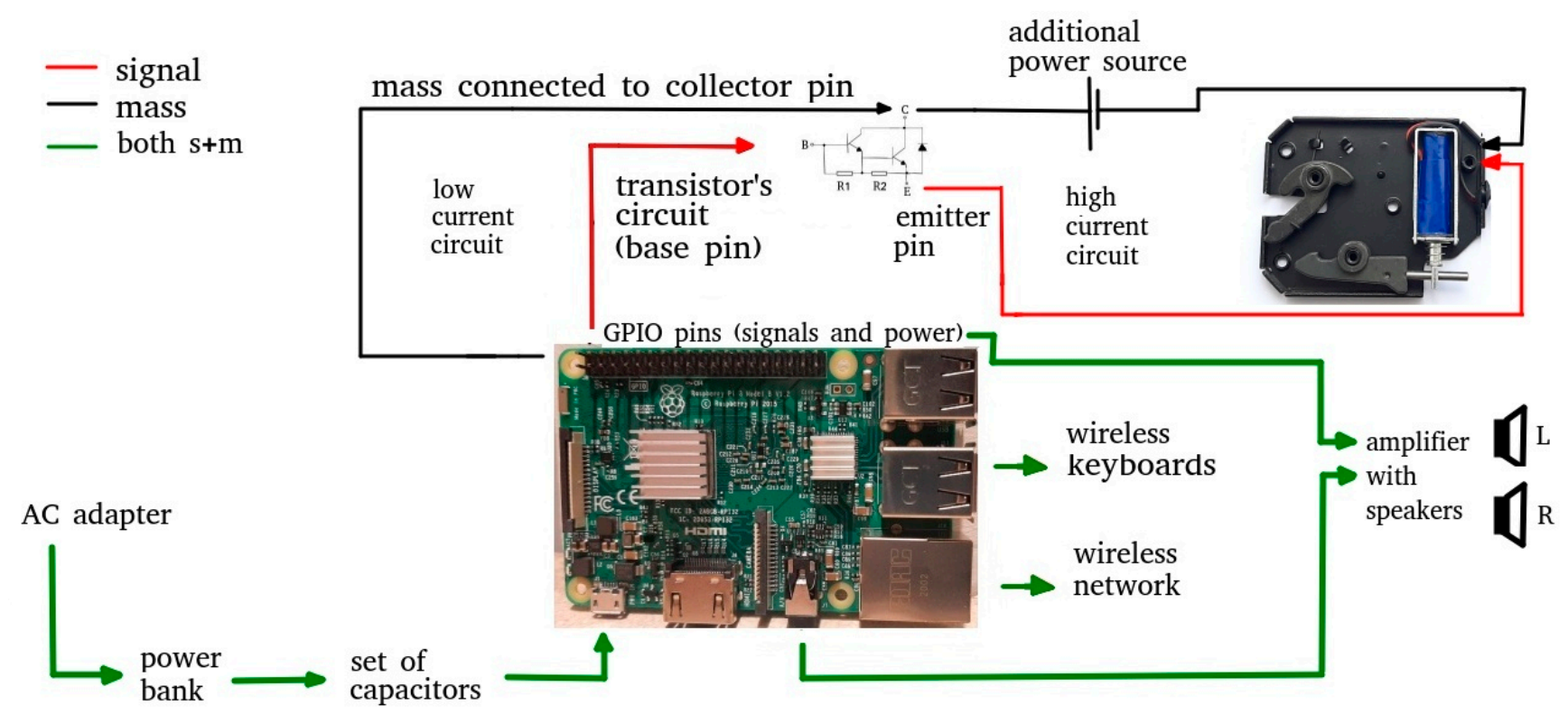

Figure 9. All the elements connected in the one coherent system (logical layout) presented in a simplified manner for the one locking mechanism only.

The early results turned out to be very promising. The first prototype was working. However, it was not free of, so called, childhood ailments. It means, the machine had some shortcomings resulting from not enough advanced or developed testing processes and also from lack of experience of the company in realization of similar projects.

The main drawback was the fact that when opening the machine to do the maintenance, the connections of some locks was not reliable enough and after the maintenance part of the locks did not work properly. For example, one could hear they are working, but not strong enough to release the ratchet. The connections of all the locks have been improved and the problem vanished.

Another problem noticed in the early phase of using the machine was also related to improper work of locks. Sometimes, after doing reset of the machine, it turned out that some locks were almost open, even if required to be closed. The reason was the improper signal from the controller, that did not stop all opening signals coming passing to the transistors and locks. The software solution was implemented. The part of additional code was added in the front of the core program code. The purpose of this additional code was to open the GPIO port for each lock (for a fraction of a second) and close it immediately. This action was setting the ports of the microcomputer to definitely locked, ensuring the safety of the documents in the machine.

The next improvement of the system was made after six months of using the machine, which stopped responding during night. The most suspected factor was some electrical anomaly. An interview was conducted with the security employees working in the building and they confirmed that there were power anomalies in the electrical network (i.e., security computers shut down and restarted) not only one night, but a few times a month in general. This means that the power bank in the machine works fine, if the machine stopped responding for the first time under such operating conditions. To solve this issue and avoid problems in the future, an additional UPS adaptor was mounted supplying a stable reserve power source.

Another disadvantage was the fact that operator (employee) of the machine, the person who leaves the documents inside, may mistype or forget the right code he or she inputted to the machine. A discussion occurred about the possibility of improvement in this area. The employee responsible for the development of the project proposed the implementation of an additional function to the solution (machine). The microcomputer was connected to the company Wi-Fi network remotely and to the Internet. The internal 
micro-controller was reprogrammed to send an e-mail every time the secret code is being recorded in the database. The content of the message is the number of the box and the secret code. The new, dedicated to this purpose only, e-mail address was created on the company's server. This way, all the employees were informed that the next package of documents is in the machine and knew precisely which boxes were occupied. Moreover, this way, no one could forget or mistype the code, since when informing the client, the right code was written right there in the e-mail message. The good practice appeared, that employees simply started to forward the message automatically generated by the machine directly to the clients. Interestingly, another discussion emerged. The employees wanted to know if it is possible to enrich the solution with one more function; to send the e-mail report every time any client uses its secret code. The software of the machine was perfected in the above-mentioned way and the function became available a few days later. Specifically, this improvement resulted in two advantages. First, the employee did not have to check if the client received the documents, which turned out to be very useful. Second, the machine reported also the misuses of the codes, thus, this way it is easy to find out if anyone is trying to get to another box or doing some verification, which will happen if they enter the wrong code. All the employees considered this a significant step towards increasing the general safety level.

Another safety-related discussion arose in relation to the service code that must be inputted into the machine in order to enter the service mode. The concerns were raised by the fact that the code is entered from a keyboard that is also used by customers. Theoretically, it could be possible that some client could randomly press some keys and, being lucky enough, input the service code. The solution to improve the level of security was to provide two separate keyboards, one alphanumerical for employees and the other, numerical, only for customers. The service code was set as a string of letters (service code turned into a password). This way, it is impossible to enter the password coincidentally. Moreover, even if the customer knew the password, it would be impossible to enter it with a numerical keypad. Moreover, the keypads are wireless, which is a good solution, because the machine cannot be damaged by an impact in the keyboard. The additional reason that a numerical keypad is the right solution in terms of security improvement is the limitation of the keys accessible to the customer. Each programmer often manipulates such keys as Alt, Ctrl, Shift, Tab, Del, Ins, and alphabetical keys. Denying open access to such keys improves security. Moreover, the fact that the machine does not require operation via touch screen was also found as an advantage, as it avoids the weak point in the security of the entire system.

An additional level of security was obtained through making the decision of placing the machine into the vestibule of the office. This means each client who wants to take the documents from the machine must retrieve the key from the available for 24-h facility's gatehouse. This requires a power of attorney to take the key. The porter checks the identity card or passport each time when asked for the key. This way the access to the machine is limited, and each key retrieval is monitored and recorded.

In order to verify, if the solution is able to withstand long term operation time, the additional test was carried out. The suspicion was that the operating system in the microcomputer does so many cycles of reading and writing that after not a long time, the internal memory card may fail. After reviewing the professional knowledge about the industry standards for performance of memory cards used in the solution and identification of number of read and written cycles, it turned out that the thread is not significant in this case. The type of used memory card should withstand at least a few years of failure-free operation.

\section{Conclusions}

The final result exceeded the expectations of the project team, leading to strengthening of the competitive position of the company. It strengthened its competitive position through adding a strong point, the significant advantage to its offer: the ability to release the documents at any time with regard to high security standards. The programmable 
microcomputer unit is controlling the flow of electrical impulses and finally generates the electromagnetic energy in order to open the lock to release the package of documents to the client. Moreover, the long-term level of costs of such a solution seems to be very low. During the one year of operation period, two malfunctions took place, each was repaired in just $3 \mathrm{~h}$ (repair and improvement, labor only, no spare parts needed). Any further maintenance, repair, or development can be done at very affordable prices, at non-available on the market labor cost, which will potentially further strengthen the impact of the solution on the competitiveness of the company. The improvement in terms of competitiveness of the company and data safety has been gained. The success of this project proves that, in some cases, it is worth to develop the necessary solution within the resources of the company rather than buying one from an external enterprise. The authors believe that the described solution is better than any other commercially available. First of all, it fully serves its purpose. Second, it fits the capital needs of the micro-sized company in terms of creation, maintenance, and improvement options. From the technical point of view, the documents always can be sent electronically and, in fact, the company whose solution is described in this article sends documents electronically every day. However, there are cases when clients expect to have the documents in originals, for example legal acts require that, or the utmost importance of the papers processed means that the client does not wish to digitize and send them via the Internet (i.e., the public network). The hypothesis that the creation of an appropriate device that meets the assumed criteria is possible within the resources possessed by a micro-sized company has been accepted.

Author Contributions: Conceptualization T.C. and D.K.-T.; Formal analysis T.C.; Funding acquisition M.I. and D.K.-T.; Methodology T.C., D.K.-T. and M.I.; Visualization T.C.; Writing-original draft T.C.; Writing-review \& editing D.K.-T. and M.I. All authors have read and agreed to the published version of the manuscript.

Funding: Research and publication were financed by the statutory research fund of the Czestochowa University of Technology SPB-600/3016/2021.

Institutional Review Board Statement: Not applicable.

Informed Consent Statement: Not applicable.

Data Availability Statement: Not applicable.

Conflicts of Interest: The authors declare no conflict of interest.

\section{References}

1. Earl, M. Knowledge Management Strategies: Toward a Taxonomy. J. Manag. Inf. Syst. 2001, 18, 215-233. [CrossRef]

2. Mokhtar, S.; Hussin, N.; Tokiran, N.S.M.; Wahab, H.; Ibrahim, A. Digital Transformation in Information Management. Int. J. Acad. Res. Bus. Soc. Sci. 2020, 10, 1453-1460. [CrossRef]

3. Anand, V.; Manz, C.C.; Glick, W.H. An Organizational Memory Approach to Information Management. Acad. Manag. Rev. 1998, 23, 796. [CrossRef]

4. Schwenk, C.R. Information, Cognitive Biases, and Commitment to a Course of Action. Acad. Manag. Rev. 1986, 11, 298. [CrossRef]

5. Gałecki, A. Contemporary Conditions of Information Security. Syst. Saf. Hum. Tech. Facil. Environ. 2021, 3, 289-295. [CrossRef]

6. Buhalis, D.; Law, C.H.R. Progress in information technology and tourism management: 20 years on and 10 years after the Internet-The state of eTourism research. Tour. Manag. 2008, 29, 609-623. [CrossRef]

7. ISO/IEC 27000: Information Security Management Systems-Overview and Vocabulary, 5th ed.; International Organization for Standardization (ISO/IEC JTC 1/SC 27): Geneva, Switzerland, 2018.

8. ISO/IEC 27001: Information Security Management Systems-Requirements, 2nd ed.; International Organization for Standardization (ISO/IEC JTC 1/SC 27): Geneva, Switzerland, 2013.

9. ISO/IEC 27002: Code of Practice for Information Security Controls, 2nd ed.; International Organization for Standardization (ISO/IEC JTC 1/SC 27): Geneva, Switzerland, 2013.

10. Wang, P. Information systems solutions for transborder data flow problems for multinational companies. Int. J. Inf. Manag. 1993, 13, 29-40. [CrossRef]

11. Hartmann, L.; Metternich, J. Waste in value streams caused by information flow: An analysis of information flow barriers and possible solutions. Procedia Manuf. 2020, 52, 121-126. [CrossRef] 
12. Hosseini, S.; Fallon, G.; Weerakkody, V.; Sivarajah, U. Cloud computing utilization and mitigation of informational and marketing barriers of the SMEs from the emerging markets: Evidence from Iran and Turkey. Int. J. Inf. Manag. 2019, 46, 54-69. [CrossRef]

13. Klimecka-Tatar, D. Analysis and Improvement of Business Processes Management-Based on Value Stream Mapping (VSM) in Manufacturing Companies. Pol. J. Manag. Stud. 2021, 23, 213-231. [CrossRef]

14. Nurmadewi, D.; Er, M. Analyzing Linkage Between Business Process Management (BPM) Capability and Information Technology: A Case Study in Garment SMEs. Procedia Comput. Sci. 2019, 161, 935-942. [CrossRef]

15. Park, J. Evaluating a mobile data-collection system for production information in SMEs. Comput. Ind. 2015, 68, 53-64. [CrossRef]

16. Partanen, J.; Kohtamäki, M.; Patel, P.C.; Parida, V. Supply chain ambidexterity and manufacturing SME performance: The moderating roles of network capability and strategic information flow. Int. J. Prod. Econ. 2020, 221, 107470. [CrossRef]

17. Ricci, R.; Battaglia, D.; Neirotti, P. External knowledge search, opportunity recognition and industry 4.0 adoption in SMEs. Int. J. Prod. Econ. 2021, 240, 108234. [CrossRef]

18. Chajduga, T. Information security management in an individual documentomat project. World Sci. News 2019, $122,32-43$.

19. Pietraszek, J.; Radek, N.; Goroshko, A.V. Challenges for the DOE methodology related to the introduction of Industry 4. Prod. Eng. Arch. 2020, 26, 190-194. [CrossRef]

20. Lu, J.-B.; Liu, Z.-J.; Tulenty, D.; Tsvetkova, L.; Kot, S. Implementation of Stochastic Analysis in Corporate Decision-Making Models. Mathematics 2021, 9, 1041. [CrossRef]

21. Kuo, J.-Y. A document-driven agent-based approach for business processes management. Inf. Softw. Technol. 2004, 46, 373-382. [CrossRef]

22. Liu, S.; McMahon, C.; Culley, S. A review of structured document retrieval (SDR) technology to improve information access performance in engineering document management. Comput. Ind. 2008, 59, 3-16. [CrossRef]

23. Senarathne, C.W.; Wei, J. The impact of patent citation information flow regarding economic innovation on common stock returns: Volume vs. patent citations. Int. J. Innov. Stud. 2018, 2, 137-152. [CrossRef]

24. Kuryło, P.; Wysoczański, A.; Bonarski, P. Knowledge and Information Management. Syst. Saf. Hum. Tech. Facil. Environ. 2021, 3, 1-10. [CrossRef]

25. Broek, M.A.U.H.; Teunter, R.H.; de Jonge, B.; Veldman, J. Joint condition-based maintenance and load-sharing optimization for two-unit systems with economic dependency. Eur. J. Oper. Res. 2021, 157, 54. [CrossRef]

26. Schlichter, B.R.; Buchynska, T. Soft skills of delivery managers in a co-sourced software project. Procedia Comput. Sci. 2021, 181, 905-912. [CrossRef]

27. Vaio, A.D.; Palladino, R.; Pezzi, A.; Kalisz, D.E. The role of digital innovation in knowledge management systems: A systematic literature review. J. Bus. Res. 2021, 123, 220-231. [CrossRef]

28. Hadid, W.; Al-Sayed, M. Management accountants and strategic management accounting: The role of organizational culture and information systems. Manag. Account. Res. 2021, 50, 100725. [CrossRef]

29. Hodel-Widmer, T.B.; Dittrich, K.R. Concept and prototype of a collaborative business process environment for document processing. Data Knowl. Eng. 2005, 52, 61-120. [CrossRef]

30. Forno, A.J.D.; Pereira, F.A.; Forcellini, F.A.; Kipper, L.M. Value Stream Mapping: A study about the problems and challenges found in the literature from the past 15 years about application of Lean tools. Int. J. Adv. Manuf. Technol. 2014, 72, 779-790. [CrossRef]

31. Haraldsdottir, R.K.; Gunnlaugsdottir, J.; Hvannberg, E.T.; Christensen, P.H. Registration, access and use of personal knowledge in organizations. Int. J. Inf. Manag. 2018, 40, 8-16. [CrossRef]

32. Farmansyah, M.H.A.; Isnalita, I. Information and Communication Technology in Organizational Performance of Local Government. Pol. J. Manag. Stud. 2020, 22, 127-141. [CrossRef]

33. Kalczynski, P.J.; Chou, A. Temporal Document Retrieval Model for business news archives. Inf. Process. Manag. 2005, 41, 635-650. [CrossRef]

34. Kao, C.H.; Liu, S.T. Development of a Document Management System for Private Cloud Environment. Procedia Soc. Behav. Sci. 2013, 73, 424-429. [CrossRef]

35. Żywiołek, J.; Rosak-Szyrocka, J.; Jereb, B. Barriers to Knowledge Sharing in the Field of Information Security. Manag. Syst. Prod. Eng. 2021, 29, 114-119. [CrossRef]

36. Asamoah, D.; Agyei-Owusu, B.; Andoh-Baidoo, F.; Ayaburi, E. Inter-organizational systems use and supply chain performance: Mediating role of supply chain management capabilities. Int. J. Inf. Manag. 2021, 58, 102195. [CrossRef]

37. Anciaux, N.; Bonnet, P.; Bouganim, L.; Nguyen, B.; Pucheral, P.; Popa, I.S.; Scerri, G. Personal Data Management Systems: The security and functionality standpoint. Inf. Syst. 2019, 80, 13-35. [CrossRef]

38. Ayaz, A.; Yanartaş, M. An analysis on the unified theory of acceptance and use of technology theory (UTAUT): Acceptance of electronic document management system (EDMS). Comput. Hum. Behav. Rep. 2020, 2, 100032. [CrossRef]

39. Rolland, K.-H.; Hanseth, O. Managing Path Dependency in Digital Transformation Processes: A Longitudinal Case study of an Enterprise Document Management Platform. Procedia Comput. Sci. 2021, 181, 765-774. [CrossRef]

40. Grossman, R.; Gu, Y.; Sabala, M.; Zhang, W. Compute and storage clouds using wide area high performance networks. Future. Gener. Comput. Syst. 2009, 25, 179-183. [CrossRef]

41. Chieu, T.C.; Zeng, L. Service-Oriented Approach for Implementing an Extensible Content Management System. In Proceedings of the 2008 IEEE Congress on Services Part. II (Services-2 2008), Beijing, China, 23-26 September 2008; pp. 96-103. [CrossRef] 
42. Heinicke, A.; Liao, C.; Walbaum, K.; Bützler, J.; Schlick, C.M. User Centered Evaluation of Interactive Data Visualization forms for Document Management Systems. Procedia Manuf. 2015, 3, 5427-5434. [CrossRef]

43. Kapler, M. Barriers to the implementation of innovations in information systems in SMEs. Prod. Eng. Arch. 2021, 27, 156-162. [CrossRef]

44. Ingaldi, M.; Klimecka-Tatar, D. People's Attitude to Energy from Hydrogen-From the Point of View of Modern Energy Technologies and Social Responsibility. Energies 2020, 13, 6495. [CrossRef]

45. Klapita, V. Implementation of Electronic Data Interchange as a Method of Communication Between Customers and Transport Company. Transp. Res. Procedia 2021, 53, 174-179. [CrossRef]

46. Morrison, J.; Sheng, O.R.L. Communication technologies and collaboration systems: Common domains, problems and solutions. Inf. Manag. 1992, 23, 93-112. [CrossRef]

47. Tsai, H.P.; Compeau, D.R. Understanding and measuring formal communication quality for technology implementation: A test during the anticipation stage. J. Strat. Inf. Syst. 2021, 30, 101669. [CrossRef]

48. Zraková, D.; Kubina, M.; Koman, G. Influence of Information-communication System to Reputation Management of a Company. Procedia Eng. 2017, 192, 1000-1005. [CrossRef]

49. Caldeira, M.; Serrano, A.; Quaresma, R.; Pedron, C.; Romão, M. Information and communication technology adoption for business benefits: A case analysis of an integrated paperless system. Int. J. Inf. Manag. 2012, 32, 196-202. [CrossRef]

50. Sekhar, S.R.M.; Siddesh, G.M.; Manvi, S.; Dosaya, V. Introduction to Healthcare Information Management and Machine Learning. In Studies in Big Data; Springer International Publishing: Singapore, 2021; Volume 88, pp. 3-22.

51. Kabak, Y.; Dogac, A. A survey and analysis of electronic business document standards. ACM Comput. Surv. 2010, 42, 1-31. [CrossRef]

52. Cristani, M.; Bertolaso, A.; Scannapieco, S.; Tomazzoli, C. Future paradigms of automated processing of business documents. Int. J. Inf. Manag. 2018, 40, 67-75. [CrossRef]

53. Sun, J.; Lei, K.; Cao, L.; Zhong, B.; Wei, Y.; Li, J.; Yang, Z. Text visualization for construction document information management. Autom. Constr. 2020, 111, 103048. [CrossRef]

54. Stacho, Z.; Stachová, K.; Papula, J.; Papulová, Z.; Kohnová, L. Effective Communication in Organisations Increases their Competitiveness. Pol. J. Manag. Stud. 2019, 19, 391-403. [CrossRef]

55. Lies, J. Internal communication as power management in change processes: Study on the possibilities and the reality of change communications. Public Relations Rev. 2012, 38, 255-261. [CrossRef]

56. Barendsen, W.; Muß, A.C.; Silvius, G. Exploring team members' perceptions of internal sustainability communication in sustainable project management. Proj. Leadersh. Soc. 2021, 2, 100015. [CrossRef]

57. Verčič, A.T.; Špoljarić, A. Managing internal communication: How the choice of channels affects internal communication satisfaction. Public Relations Rev. 2020, 46, 101926. [CrossRef]

58. Matuszny, M. Building decision trees based on production knowledge as support in decision-making process. Prod. Eng. Arch 2020, 26, 36-40. [CrossRef]

59. Lee, Y.; Yue, C.A. Status of internal communication research in public relations: An analysis of published articles in nine scholarly journals from 1970 to 2019. Public Relations Rev. 2020, 46, 101906. [CrossRef] 